\title{
Active learning materials for molecular and atomic spectroscopy
}

\author{
Thomas J. Wenzel
}

Published online: 11 July 2014

(C) Springer-Verlag Berlin Heidelberg 2014

\section{Introduction}

Evidence from a growing body of research shows that classes taught in a lecture format are not an effective learning environment for many people. One problem with lectures is that those in the audience are often distracted and not paying attention to the lecturer. This leads to incomplete notes and an inability to follow the logic incorporated into the presentation [1-5]. Another problem is that learning in a lecture requires a variety of skills, for example excellent note-taking ability, excellent auditory skills, and a high working memory capacity [6]. Many people do not possess these attributes. It is difficult in a lecture environment for the instructor to meaningfully probe the students' understanding of the topic being covered and discover whether they have critical misunderstandings that are compromising their ability to learn the material. Furthermore, many students are inhibited from asking questions in lectures or do not realize that they are not actually understanding the material being presented [6].

A recent article in this journal [7] highlighted how knowledge is constructed in the mind of the learner [8]. To construct knowledge students must engage with the material in a process that is more active than is possible in a lecture. Students also need to connect new topics being learned to knowledge they already possess [9-11]. In a lecture format, the instructor usually tells the students what the linkages are between the new topic and previous knowledge. Approaches in which the students must first draw on their own knowledge when presented with a new topic are more effective at promoting learning. Asking students to draw on their own knowledge will show that many students have incorrect ideas and beliefs about fundamental concepts [12]. Learning will be more

T. J. Wenzel $(\bowtie)$

Department of Chemistry, Bates College, Lewiston, ME 04240, USA

e-mail: twenzel@bates.edu effective when students are forced to confront and correct their misperceptions.

Studies show that an active classroom environment in which students work in small groups on questions or problems posed by the instructor is effective at promoting learning $[6$, 13-26]. A recent meta-analysis of 225 research studies found that test scores were higher and the number of failures was lower for active learning versus lecture classes [27]. One inhibition to the use of active learning in the undergraduate analytical chemistry curriculum is the dearth of active learning materials available to instructors. A previous article described active learning materials suitable for coverage of chemical equilibrium and separation science in the undergraduate analytical chemistry curriculum [28]. In this article, I describe a set of active learning materials suitable for coverage of molecular and atomic spectroscopy in the undergraduate analytical chemistry curriculum. These materials are freely available through the Active Learning site of the Analytical Sciences Digital Library [29] under the creative commons copyright. They are designed in such a way that instructors can use portions of them, only, in their courses or modify them to suit their own needs.

\section{Active learning materials}

The materials developed for active learning of molecular and atomic spectroscopy consist of a set of learning objectives, inclass question sets, textual material to support the in-class questions, and an instructor's manual [30]. In addition to general background information on spectroscopic methods, materials covering ultraviolet-visible (UV-Vis) absorption, molecular luminescence, infrared, Raman, and atomic spectroscopy are provided. Active learning in the form of group work on in-class questions is effective when covering spectroscopy because students have information from previous 
courses, for example general and organic chemistry, that form the underlying basis of many of the concepts needed to comprehend spectroscopic methods. The process of recalling this information in the development of questions is useful for promoting their learning of the material.

In-class activities that develop a general background of spectroscopy ask the students to recall the relationship between energy and frequency and energy and wavelength of electromagnetic radiation. They are then asked to list and rank by energy the different types of electromagnetic radiation. On the basis of knowledge from organic chemistry, they can usually determine processes associated with the absorption of IR, radiofrequency, and UV-Vis radiation, but they are often uncertain about the exact processes that occur in the absorption or emission of gamma rays, X-rays, and microwave radiation. Additional questions in this set develop the concepts within Beer's Law and begin considering how the matrix affects spectroscopic measurements.

A homework assignment delves more specifically into instrument components (e.g., continuum and laser radiation sources, dual versus single-beam spectrophotometers, monochromators, detectors). Students use available resources, for example the Analytical Sciences Digital Library, to answer the questions on the assignment; these are then discussed in class.

In developing UV-Vis absorption and molecular fluorescence, questions with the objective of investigating the differences between atomic and molecular spectra, transition probability, contributions to spectral broadening, the effect of conjugation and non-bonding electrons, the effect of polar compared with non-polar solvents, and the utility of UV-Vis absorption spectroscopy for qualitative and quantitative analysis are developed. Questions in the molecular luminescence unit ask students to investigate aspects of singlet and triplet states, relative lifetimes of different excited states, and the distinction between fluorescence and phosphorescence. Other questions focus on instrument design, the difference between excitation and emission spectra, variables that affect fluorescence quantum yields, $\mathrm{pH}$-dependent changes that may occur in spectra, and the effect of structural rigidity on quantum yield.

In the units on infrared and Raman spectroscopy, the importance of selection rules is developed and the differences in IR and Raman active vibrations for simple molecules, for example carbon dioxide and water, are investigated. The operation of a Michelson interferometer and advantages of FTIR over conventional IR are examined. The distinction between the Stokes and anti-Stokes lines and aspects of the locations and intensities of these lines in Raman spectroscopy are developed.

In the unit on atomic spectroscopy, after a presentation on atomization sources, students are asked to consider the advantages and disadvantages of flames and furnaces. They examine why hollow-cathode sources are used instead of continuum sources in most commercial atomic absorption spectrophotometers, and are challenged to see if they can suggest design features that would enable someone to account for flame noise, spectral interferences, for example molecular absorption and scatter, excessive ionization, and other chemical interferences.

\section{Responsibility of the instructor in active learning exercises}

The instructor is especially important in the effective use of the active learning exercises described herein. Active learning exercises can be designed in two different manners. One design gives a series of questions that essentially guides the students through, step-by-step, the different thought processes needed to solve a question. Another way to design an active learning exercise is to ask a rather broad and open-ended question such that students need to use knowledge and concepts they possess that are relevant to answering the question. For example, one of the questions on the problem sets described herein asks the students to consider why a hollowcathode lamp is used instead of a continuum source in most commercial instruments for atomic absorption spectroscopy (AAS). The activities described herein mostly consist of broad, open-ended questions.

In such a process it is important that the instructor participates actively in listening to the conversations taking place in the groups and pointing out things under consideration that are either relevant or irrelevant to answering the question. For example, in the discussion of why a hollow-cathode lamp is often used instead of a continuum source in AAS, students rarely think of comparing the atomic line width with the bandwidth of conventional monochromators. They often consider source power or enquire whether conventional continuum sources have the correct wavelengths of light. Even when prompted to consider line width, they may be baffled until further prompted to draw the output from a conventional continuum source with the atomic absorption superimposed over it. After developing this, we then discuss how researchers have shown that it is possible to use a continuum source with AAS if the source has sufficiently high power across the entire range of wavelengths and the monochromator has high enough resolution to reduce the bandwidth so that it is less than or equal to the half width of the atomic line.

Sometimes, it becomes apparent that a group is completely misinterpreting the question and needs further explanation to understand what is being asked. When this occurs, it is likely that other groups may have the same misinterpretation such that it is worth gaining the attention of the entire class to clarify what is being asked (I have found this especially important in larger classes with more groups.) During progression through a broad, open-ended question there are likely to be key conceptual points along the way that the students must understand when solving the problem (e.g., continuum 
sources do have sufficient power and do cover the appropriate wavelengths needed for measurements in AAS). In this case, it is valuable ask the class for their attention and summarize each of these for the entire class before allowing the groups to continue with the problem. At the end of the problem, it is important to spend a few minutes summarizing the outcome for the entire class. Only after a question or problem is answered, do I provide the students with the accompanying textual material. I encourage them to read it that evening while the topic is fresh in their mind.

Not all topics covered in the spectroscopy portion of an analytical course are amenable to group work by the students. Some preliminary material the students need to understand (e.g., different atomization courses) are likely to be best covered in a lecture format. In this case, it is desirable to provide the students with the appropriate textual material before the lecture as a reading assignment. If they read the text, it will enable them to ask questions to clarify topics they find confusing. The instructor's manual gives advice and guidance on topics which can be covered using a lecture format and those more amenable to having the students work in groups. The manual also provides examples of students' common misconceptions for some of the questions.

\section{Summary}

Research studies show that having students work in groups to answer questions or problems is effective at promoting learning. One of the impediments to the utilization of active learning in undergraduate analytical chemistry courses has been the dearth of materials available. In this report I describe a set of active learning materials that cover many of the basic concepts in molecular and atomic spectroscopy that are incorporated into undergraduate analytical chemistry courses. These materials are designed in such a way that they can easily be modified or that only a portion of the materials need be used. Learning objectives, textual material, and an instructor's manual are also provided. All of the materials are freely available through the Active Learning site on the Analytical Sciences Digital Library under the creative commons copyright.

Acknowledgments I thank the National Science Foundation for supporting this work through a Transforming Undergraduate Education in STEM Award (DUE-1118600).

\section{References}

1. Pollio H (1984) What students think about and do in college lecture classes. In Teaching-Learning Issues; University of Tennessee, Learning Research Center: Knoxville, 3-18
2. Penner JG (1984) Why many college teachers cannot lecture: how to avoid communication breakdown in the classroom. Charles C. Thomas, Springfield

3. Stuart J, Rutherford RJD (1978) Medical student concentration during lectures. Lancet 2:514-516

4. Verner C, Dickinson G (1967) The lecture: an analysis and review of research. J Educ Psychol 17:85-100

5. Wenzel TJ (1999) The lecture as a learning device. Anal Chem 71: 817A-819A

6. Johnson DW, Johnson RT, Smith KA (1991) Cooperative Learning: increasing college faculty instructional productivity. ASHE-ERIC Higher Education Report No 4, The George Washington University, Graduate School of Education and Human Development, Washington, DC

7. Cooper MM (2014) Evidence-based reform of teaching and learning. Anal Bioanal Chem 406:1-4

8. Bodner GM (1986) Constructivism: a theory of knowledge. J Chem Educ 63:873-877

9. Novak JD (1977) A theory of education. Cornell University, Ithaca

10. Bretz SL (2001) Novak's theory of education: human constructivism and meaningful learning. J Chem Educ. doi:10.1021/ ed078p1107.6

11. Ausubel DP (1968) Educational psychology: a cognitive view. Holt, Rinehart, and Winston, New York

12. Singer SR, Nielsen NR, Schweingruber HA (2012) Discipline-based education research: understanding and improving learning in undergraduate science and engineering. National Academies Press, Washington DC

13. Teichert MA, Stacy AM (2002) Promoting understanding of chemical bonding and spontaneity through student explanation and integration of ideas. J Res Sci Teach 39:464-496

14. Cooper MM, Cox CT, Nammouz M, Case E, Stevens R (2008) An assessment of the effect of collaborative groups on students' problem solving strategies and abilities. J Chem Educ $85: 866-872$

15. Bransford J, Brown AL, Cocking RR (2000) How people learn: brain, mind, experience and school. National Academies Press, Washington, DC

16. Murray HG (1985) In: Donald JG, Sullivan AM (eds) Using research to improve teaching. Jossey-Bass, San Francisco

17. Blosser PE (1993) The science outlook: using cooperative learning in science education. ERIC-CSMEE, Columbus, pp 1-9

18. Allen DE, Duch BJ, Groh SE (1996) New directions in teaching and learning, vol 68. Jossey-Bass Publishers, San Francisco, pp 43-52

19. Springer L, Stanne ME, Donovan S (1997) Effects of smallgroup learning on undergraduates in science, mathematics, engineering, and technology: a meta-analysis. National Institute for Science Education: Madison, WI, http://www. wcer.wisc.edu/nise/CL1/CL/resource/R2.htm. Accessed 10 May 2014

20. Spencer JN (1999) New directions in teaching chemistry: a philosophical and pedagogical basis. J Chem Educ 76:566-569

21. Johnson DW, Johnson RT, Stanne ME (2000) Cooperative learning methods: a meta-analysis. University of Minnesota, Minneapolis: Cooperative Learning Center, http://www.tablelearning.com/ uploads/File/EXHIBIT-B.pdf. Accessed 10 May 2014

22. Bowen CW (2000) A quantitative literature review of cooperative learning effects on high school and college chemistry achievement. J Chem Educ 77:116-119

23. Terenzini PT, Cabrera AF, Colbeck CL, Parente JM, Bjorklund SA (2001) Collaborative learning vs. lecture/discussion: students' reported learning gains. J Eng Educ 90:123-130

24. Gosser DK, Cracolice MS, Kampmeier JA, Roth V, Strozak VS, Varma-Nelson P (eds) (2001) Peer-led team learning: a guidebook. Prentice-Hall, Upper Saddle River 
25. Cabrera AF, Crissman JL, Bernal EM, Nora A, Terenzini PT, Pascarella ET (2002) Collaborative learning: its impact on college students' development and diversity. J Coll Stud Dev 43:20-34

26. Springer L, Stanne ME, Donovan SS (1999) Effects of small-group learning on undergraduates in science, mathematics, engineering, and technology: a meta-analysis. Rev Educ Res 69:21-51

27. Freeman S, Eddy SL, McDonough M, Smith MK, Okoroafor N, Jordt H, Wenderoth MP (2014) Active learning increases student performance in science, engineering and mathematics. Proc Natl Acad Sci. doi:10.1073/pnas.1319030111

28. Wenzel TJ (2011) Active learning materials for equilibrium and separation science. Anal Bioanal Chem 400:637-640

29. Analytical Sciences Digital Library, http://www.asdlib.org. Accessed 10 May 2014; Curriculum materials described herein, http:// community.asdlib.org/activelearningmaterials/. Accessed 10 May 2014

30. Molecular and Atomic Spectroscopy active learning unit, http:// www.community.asdlib.org/activelearningmaterials/molecular-andatomic-spectroscopy/. Accessed 10 May 2014

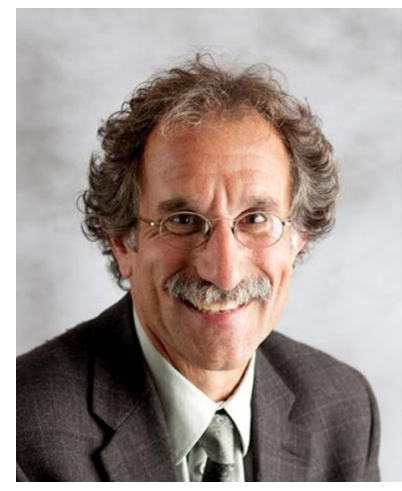

Thomas J. Wenzel is the Charles A. Dana Professor of Chemistry at Bates College in Lewiston, Maine, USA. He currently conducts research, with the aid of undergraduate students, on chiral NMR shift reagents. His research accomplishments were recognized with the 2010 American Chemical Society Award for Research at an Undergraduate Institution. He is active in efforts to reform the undergraduate analytical chemistry curriculum to include inquiry and project-based experience. In recognition of his educational activities he was given the 1999 J.C. Giddings

Award for Excellence in Education sponsored by the Analytical Division of the American Chemical Society. More information about his activities can be found at http://www.bates.edu/chemistry/faculty/thomas-wenzel. 